\title{
Erratum
}

\section{Aluminum's Involvement in the Progression of Alzheimer's Disease}

\section{J.R. Walton}

[Journal of Alzheimer's Disease 35(1), 2013, 7-43, http://dx.doi.org/10.3233/JAD-121909]

On page 16, the last line of the legend for Fig. 3 reads:

"Reproduced from [61] with permission from Elsevier."

It should read:

"Reproduced from [62] with permission from Elsevier."

On page 23 , the last sentence on this page reads:

"AD patients absorb about $40 \%$ more aluminum from a standardized aluminum dose."

It should read:

"AD patients absorb about $64 \%$ more aluminum from a standardized aluminum dose." 